\title{
Experiential Basis of Meaning in a Semantic Associative Test: A Move toward an Embodied Explanation of Primary Metaphor
}

\section{Habibollah Ghassemzadeh ${ }^{*}$, Jamal Abedi², Akram Khamseh ${ }^{3}$, Uta Sassenberg4, Maryam Rahat ${ }^{5}$, Elham Eshtad6, Mansooreh Rajabloo ${ }^{6}$}

${ }^{1}$ Tehran University of Medical Sciences, Tehran, Iran

${ }^{2}$ University of California at Davis, Davis, CA, USA

${ }^{3}$ Alzahra University, Tehran, Iran

${ }^{4}$ Berlin School of Mind and Brain, Berlin, German

${ }^{5}$ American Creative Academy, Kuwait, Kuwait

${ }^{6}$ Private Practice, Tehran, Iran

Email: *hghassemzadeh@tums.ac.ir

How to cite this paper: Ghassemzadeh, $\mathrm{H}$., Abedi, J., Khamseh, A., Sassenberg, U., Rahat, M., Eshtad, E., \& Rajabloo, M. (2017). Experiential Basis of Meaning in a Semantic Associative Test: A Move toward an Embodied Explanation of Primary Metaphor. Psychology, 8, 1895-1918.

https://doi.org/10.4236/psych.2017.812123

Received: August 24, 2017

Accepted: October 8, 2017

Published: October 11, 2017

Copyright $\odot 2017$ by authors and Scientific Research Publishing Inc. This work is licensed under the Creative Commons Attribution International License (CC BY 4.0).

http://creativecommons.org/licenses/by/4.0/

\begin{abstract}
The concept of meaning has undergone many changes in the course of scientific study of language, thought and behavior. At first, it was explained as something which happens in the mind and then is changed to a product of association of ideas. Today, however, new meaning of meaning has emerged with the emphasis on the experiential basis as has been formulated in the concept of metaphoric expression. In this paper, we report a preliminary study on meaning as measured by a semantic-associative test in four different cultures (Iranian, German, Arabic and American). The findings have been explained in the framework of the primary metaphors and embodiment theory.
\end{abstract}

\section{Keywords}

Meaning, Semantic Differential, Association Link, Figurative Meaning, Embodiment, Primary Metaphor

\section{Introduction: The Meaning of Meaning}

Meaning has been considered as one of the most complicated and controversial terms in the history of linguistics, philosophy and cognitive psychology.

According to Ogden and Richards (1923), whose book "Meaning of Meaning" appeared more than nine decades ago, "No less than sixteen groups of definitions [of meaning] can be profitably distinguished..." (p. 74). One of the distinc- 
tions, which have a relevance to the psychological aspects of meaning, is between "sense" and "reference", originally formulated by modern formal logic founder Gottlob Frege. Reference or denotation of an expression is the thing that it stands for. The part of meaning that is not its reference is termed its sense (Frege, 1892/1970). The sense of a word means "its place in a system of relationships which it contracts with other words in vocabulary” (Lyons, 1968: 427). Sense and reference are complementary aspects of meaning. Sense pertains to the relationship between a word and other words in the language. Reference deals with relationships between a word and what it stands for in the world (Graham, 1985: 96). To use language in a meaningful manner, we need to play attention to both properties (Carroll, 1999:105-108).

There has been a tendency in psycholinguistic tradition to make a distinction between another two aspects of meaning: denotation and connotation. Denotation is the objective or dictionary meaning of a word; and connotation deals with some aspects of meaning which go beyond that which it explicitly names or describes. This aspect of meaning is mostly personal, subjective, and emotional (Carroll, 1999: 108-109). This distinction found its salient relevance to psycholinguistics in Vygotskian approach toward language and thought when these two aspects were differentiated as two categories, namely "meaning" and "sense" (Vygotsky, 1962; Luria, 1982). Meaning according to Vygotsky is a stable system of generalizations represented by a word, a system which is the same for everyone. But sense is concerned with those connections which interest us in a given situation (this concept of sense is different from Frege's terminology). As Luria (1982) states "if meaning is an objective reflection of a system of relations and associations, sense is a transformation of meaning, a selection from among all possible meanings of those which interest the person at a given moment" (pp. 44-45). Vygotsky-Luria's ideas about meaning and sense were consistent with the classic distinction between denotation and connotation which had been used in semiotics (Chandler, 2002).

\section{Measurement of Meaning}

Along with explorations about the concept of meaning and different aspects of it, the investigators started to develop and propose some tests and techniques to measure meaning of words as they occur in relation to other words or ideas in individuals. The methodology they used was mostly borrowed from psychology and it was based on different types of testing method. In this regard, perhaps the most widely known method used to investigate semantic aspect of a word was association test. In this method, subjects are given a list of words and asked to respond to each with the first word that comes to their minds. Studies have shown that such associations are elicited according to a connection that probably exists between the stimulus word and the words that seem somehow to be related to that word. This approach to investigate the semantic relations was originally proposed by Sir Francis Galton (1879, cited in Slobin, 1974) and later used 
by Kent and Rosanoff (1910) and Jung (1918).

In a version related to associative tests, Charles Osgood developed a technique called Semantic differential technique, which actually was based on an approach towards meaning. This approach was derived from his mediational theory with emphasis on the role of psychological and/or neurological variables in the formation of meaning (Slobin, 1974: 910). This type of understanding of meaning seemed very similar to Vygotsky-Luria's basic ideas about connotational meaning or as they refer as a "sense" of meaning, based on a semantic field in the mind or the brain.

Dictionaries are an important source of denotative meanings. But for detection of connotative meanings some rating scales have been designed. One of the most cited of these scales has been introduced by Charles Osgood. This instrument, called the semantic differential, has been described in several publications (Osgood, 1953; 1964; Osgood, Susi, \& Tannebaum, 1957). It has been used for a variety of purposes ranging from predicting a political election to identifying changes in personality structure. The respondent is asked to choose where his or her position lies, on a scale between two bipolar words, or a range of words or numbers ranging across a bipolar position in 3 dimensions such as evaluation (good-bad), activity (active-passive), and potency (strong-weak). These three dimensions emerged in tests of some thirty language communities around the world (Osgood, May, \& Miron, 1975).

One important outcome of using this technique in different studies was to pay more attention to the emotional aspects of meaning which was mostly neglected in previous theories and hypotheses.

Figurative meaning

Although the experiments based on such an assumption (i.e. the associative nature of meaning) were initially done in a behavioristic paradigm in which reference to mental processing was mostly avoided (Carroll, 1999: 12), one aspect of language called figurative language or indirect speech including metaphor, idiom and proverb, gradually became favorite subject for different studies with different orientations and formulations. In this respect, metaphor which had been left almost entirely to the literary and rhetoric thinkers became the most extensive and interesting area to be discussed and studied in the framework of the new emerging interdisciplinary trends.

Metaphor as a subject of cognitive psychology and cognitive science became one of the important areas of investigation as it relates to language, thought, emotion, motivation and reasoning. Many theoretical explanations were proposed (e.g. Billow, 1977; Ortony, 1975; 1979a; 1979b; Ortony, Reynolds, \& Arter, 1978). But the publication of Lakoff and Johnson's book “Metaphors We Live by" in 1980 was the starting point to consider metaphor as a cognitive tool and mechanism that changed our understanding of metaphor and its role in cognition. They introduced metaphor as a fundamental mechanism of mind which makes our world understandable and shapes our perceptions and actions in a 
systematic and organized way. One of the most important contributions of this book was the elimination of the allegedly supposed ideas about the nature of our abstract world. Metaphorical meanings were introduced as conceptual mappings that arise from correlations in our embodied experience. As Lakoff and Turner (1989) states, "What is meaningful are not the words themselves, the mere sound sequences spoken or letter sequences on page, but the conceptual content that the words evoke. Meanings are thus in people's mind, not in the words on the page" (p. 109).

\section{The Emergence of New Meaning of Meaning}

The new emerging trends in cognitive science such as embodiment theories as well as the emphasis on the centrality of metaphorical meaning in cognitive processes led some thinkers such as Johnson (2007) to believe that the dichotomy of denotative-cognitive vs. connotative-emotional meaning is more harmful than useful. Because there is no cognition without emotion and excluding emotion from the realm of meaning makes our experience without any basis of bodily engagement in this process. Johnson tried to develop a concept of embodied meaning which is much broader than the mainstream philosophy of language and thought. The basic idea in this new-emerging trend is that meaning is not something generated consciously in the relationship of an individual with the environment but it has deep down into our corporeal interaction with the world. In other words, without the involvement of our bodily processes-in different levels-we will not be able to develop any idea about the world and will not be able to reach some complicated "mental" activities such as reasoning, judgment, evaluation and decision making. Therefore, according to Johnson (2007), meaning is embodied. It arises through organism-environment interactions based on sensory-motor experiences. Meaning emerges when things are experienced in their connections with other things, events and the previous feeling and experiences (pp. 265-273). In this framework, our approach toward meaning changes from classification of meaning (as literal/figurative or denotational/connotational) to one type meaning enriched with the total experiences of a person in his/her interaction with the world. This type of meaning has many aspects consisting of emotional, cognitive, motivational and practical elements which all come together as an integrated system when we use a word or hear a word in the real world. Metaphor is an excellent indicator of such a meaning which makes even the most complicated concepts understandable and in a way explainable for us. In fact, our conceptual system is constructed on the basis of this type of meaning.

\section{Extension of Meaning and Metaphor}

Theoretically, metaphor is conceptualized as a systematic cross-domain mapping with two conceptual domains (knowledge fields) where one (target domain) is understood in terms of the other (source domain) (Gibbs, 1994; 1996; 1998; La- 
koff \& Johnson, 1999: 57-58). The most important aspect of metaphors as has been delineated by Lakoff and Johnson is the experiential basis of them. According to their views no metaphor can be understood without any experiential bases (Lakoff \& Johnson, 1980/2003: 19). Consistent with this idea we may say that metaphors consist sets of mapping between a more concrete or physical source and a more abstract target domain. Our experiences of physical objects provide the basis for a variety of metaphors-mostly analogical—through which we view events, activities, emotions, ideas, etc. as entities and substances (Lakoff \& Johnson, 1980/2003: 25). In this sense, we may conceptualize understanding an idea (subjective experience) based on a grasping an object (sensorimotor experience) (Lakoff \& Johnson, 1999: 45; Gallese \& Lakoff, 2005: 467; Johnson, 2007: 162-164). In this process, "grasping" an idea which is a subjective experience, is represented as grasping an object, which is an objective and physical experience. Therefore, a meaning which arises for "grasping" is based on a subjective experience of something which may happen in an objective world. As a matter of fact, there is an extension in the meaning of "grasping something physical" to incorporate "grasping an idea". In this case an idea becomes something graspable like anything physical such as spoon, book, pen etc. Some authors call this kind of metaphor primary metaphors-as opposed to complex or compound metaphors which mostly are schema-based formulations (Ghassemzadeh, 1999; 2005; Gibbs, 2005; Grady, 2005; Keshavarz \& Ghassemzadeh, 2008). The primary metaphor has been described with a minimal structure, which arises naturally, automatically, and unconsciously through everyday experience by means of conflation during which cross-domain associations are formed (C. Johnson, 1997 cited in Lakoff, 2008). Some examples of primary metaphors include: affection is warmth, important is big, happy is up, intimacy is closeness, and more is up. In the expression "affection is warmth" affection becomes understandable through the experience of warmth and finds an "implicational" meaning which is totally experiential. Applying the classified concept of meaning to "affection" does not make any sense. Meaning becomes incorporated in a pattern of metaphoric expression.

Lakoff (1993) argues that since primary or basic level metaphors are widely shared by humans in different cultures, may not be regarded as culture dependent. The universality hypothesis of primary metaphors stems from such an explanation (cf. Kovecses, 2005; Yu, 2008). But considering the concept of culture in its broadest sense, and viewing the behavior of individuals in a contextual situation, the universality hypothesis seems to be controversial. In fact, it is difficult to consider cognition apart from the embodied and grounded interactions with the cultural world (Deignan, 2003; Gibbs, 1999). Part of this argument is related to the structure of a metaphoric expression. Metaphors usually create meaning by embedding each experience into a system of relations that are like system of relations already we know. Therefore, a metaphorical mapping is built on an asymmetry between source and target domains. The mapping is unidirec- 
tional from source to target. Source domain is defined as being more closely related to physical experience than the target domain. By comparing "love" to a "rose", the system of relations into which we place a rose (flower, fragrance, color, beauty) is the system of relations through which we comprehend love.

The things we use as source domains vary greatly depending on the nature and characteristics of our interaction with those domains. Virtually anything is capable of being used as a metaphor. But one of the most common sources of metaphorical meaning is probably the world of nature itself. All the human beings live in nature and have an inevitable relation with natural phenomena. Natural phenomena such as river, mountain, forest, flower, tree and cloud, play the most important role in the lives of human beings and animals. In the ancient times, the classification of temperament and character had been based on fire, water, air, and earth (natural phenomena). Besides, many natural phenomena as experienced by people have become the most familiar as well as available and salient domains to interpret the other aspects of life-aspects which don't have an easy, tangible and sometimes cognizable way of explanation.

A natural phenomenon is a non-artificial event in the physical sense, and therefore not produced by humans. Nature, in the broadest sense, is equivalent to the natural world, physical world, or material world on the one hand, and also to life in general, ranging in scale from the sub-atoms to the cosmic, on the other. Natural environment not only has very important role in the physical, psychological, economic, social and cultural life of people, they have an enormous effect on the processing and representation of information in the minds of people, as well. In a sense, our physical world and mental life are interwoven and intermingled. Most of the words used by individuals of the society stem from their natural world as they interact with the different aspects of life. We live in a "meaningful" world in which we have created the meaning of many "subjective" phenomena in the process of analogical understanding of the "objective" environment. In a sense, it seems there is a tendency for extension in the "meaning" of the things that we experience in our daily life to include many aspects of life that seem unfamiliar or unexplainable for us.

\section{Associative Link as an Indicator of Metaphoric Meaning}

The extension of meaning usually takes a form of associations which happen based on the nature of the relationship that we establish with the real world. For that reason many words possess not one, but several meanings. In fact, identifying the object reference of a word is really a matter of selecting the meaning required from several possible candidates. As Lakoff and Turner (1989) indicate our understanding the world depends not on "words" per se but what the words generate in our mind. A word not only indicates an object, it also elicits several additional associations. In this way, a word becomes the central point for an entire chain of images generated by it and for words semantically connected with it. The speaker or listener selectively inhibits some of these images and ideas so 
as to choose, in the given situation, the "closest" meaning or the "implied" meaning that is needed. A process which helps to consider a meaning from all the network of associations is based on a mechanism called association. Metaphorical expressions are excellent representation of associative meanings, with one meaning as the most salient and available in the mind. We can assume that natural phenomena provide necessary information leading to saliency in metaphorical expressions.

In general, we may conclude that metaphors operate by projecting the meaning and inference structure of the source domain onto the target domain, so that we understand the target domain and reason about it in the way we would in the source domain.

\section{A Preliminary Study}

According to the new understanding of meaning as expresses itself in metaphors, a word not only indicates an object, it also elicits several relevant associations which totally generate its meaning in different contexts. In this way, a word becomes the central point for an entire chain of images generated by it and for words connected with it. The speaker or listener unconsciously inhibits some of these images and implicit words so as to choose, in the given situation, the "closest" or most "relevant" meaning. Luria (1982) calls these associative meanings as a "semantic field' which surrounds every word (pp. 15-17). A process which helps us to consider an option from the entire network of associations is based on a mechanism called inhibition. The higher the typicality of an instance, the stronger the connection between it and a given word (Martindale, 1990: 180). Metaphorical expressions are excellent representation of associative meanings, with one meaning as the most salient and available in the mind.

In a study similar to Osgood's studies, but with a different framework and purpose, we designed a simple test to study the associative meaning of words. This study was an exploration about the nature of the meaning in an associative context as well as the emergence of new experiential meaning which usually takes the form of metaphor. We combined Vygotsky-Luria's approach of semantic field with the new emerging concepts of experiential correlation and embodiment. The test consists of some words (attributes) such as "peace", "kindness", "warmth", "resistance", etc. which may be associated to nouns such as "river", "stone", "tree", "rain", etc. These nouns represent natural phenomena which play a role of source domains in a metaphoric expression. The reason we used natural phenomena was that all of the people have a relation to these phenomena and their perception is built on an experiential basis. Our main assumption was that meaning emerges when things are experienced in their connections with other things and previous experiences.

The general goal of this study was to examine the feasibility of this type rating about the attribution of some features to the nouns (natural phenomena). We treated this associative attribution as something related to the nouns which acti- 
vates a semantic field in the mind. Meaning arises out of such an activation which is highly dependent on the nature of the relation of the individual with those things in the real world. In fact we believe that experience is something which makes such an attribution or association possible. Our hypothesis is that when the individual sees the word "flower" and as an experiential option he/she tries to relate that item with a word such as "beauty", a correlation is generated between flower and beauty in his/her mind and the remembering process in the working memory selects that attribute very easily. In a sense, "beauty" becomes one of the elements of meaning for "flower". Therefore, the dictionary meaning (definition) of flower would not be enough for understanding it (i.e. relating it to the concept of beauty). It may be regarded either as a "partial" meaning or something far away from the experiential context of flower. This assumption or hypothesis is consistent with Feldman's (2008) idea that "essentially all our cultural, abstract, and theoretical concepts derive their meanings by mapping, through metaphor, to the experiential concepts ...” (p. 199). From Feldman's neural perspective, primary metaphors such as "affection is warmth" can be seen as a normal consequences of associative learning, which itself is based on Hebb's idea that "neurons that fire together, wire together" (Hebb, 1949: 70).

\section{Participants}

Participants were a sample of students from Iran $(\mathrm{N}=30)$, Germany $(\mathrm{N}=36)$, Kuwait $(\mathrm{N}=19)$, and the USA $(\mathrm{N}=18)$ (Total = 103). The languages that were studied were: Persian, Arabic, German and English. We did not have any preferred reason to include these languages except the accessibility to the people who volunteered to take part in the study (as researcher or participant).

\section{Measure}

The test consists of some words (21 attributes) such as "peace", "kindness", "warmth", "resistance", etc. which may be associated to the nouns such as "river", "stone", "tree", "rain", etc. (10 natural phenomena) (Table 1). This test is designed with the idea that reading every word generates a semantic field in the mind in which some of the elicited images, meanings or concepts are more salient than others. This salience reflects itself as an association. For example, the word "mountain" may activate a semantic network with many features such as solidity, resistance, heaviness, stability, and persistence. Among these features some of them may play a dominant role depending on the context or individual or cultural peculiarities. In this case mountain may be assessed as the source domain of expression such as "a mountain of sorrow" or "he is great as a mountain" (these expressions are used in Persian Language). The test was designed in Persian language first and then it was translated to Arabic, English and German. Some of the items had more than one equivalent in the foreign languages. We discussed the matter with the translator and came up with a test with satisfactory face validity.

Procedure

The participants were asked to read the words in row (natural phenomena) 
Table 1. A test of association.

\begin{tabular}{|c|c|c|c|c|c|c|c|c|c|c|}
\hline & $\begin{array}{c}(1) \\
\text { River } \\
(0,1,2,3)\end{array}$ & $\begin{array}{c}(2) \\
\text { Stone } \\
(0,1,2,3)\end{array}$ & $\begin{array}{c}(3) \\
\text { Tree } \\
(0,1,2,3)\end{array}$ & $\begin{array}{c}(4) \\
\text { Rain } \\
(0,1,2,3)\end{array}$ & $\begin{array}{c}(5) \\
\text { Flower } \\
(0,1,2,3)\end{array}$ & $\begin{array}{c}(6) \\
\text { Sea } \\
(0,1,2,3)\end{array}$ & $\begin{array}{c}(7) \\
\text { Cloud } \\
(0,1,2,3)\end{array}$ & $\begin{array}{c}(8) \\
\text { Mountain } \\
(0,1,2,3)\end{array}$ & $\begin{array}{c}(9) \\
\text { Wind } \\
(0,1,2,3)\end{array}$ & $\begin{array}{c}(10) \\
\text { Snow } \\
(0,1,2,3)\end{array}$ \\
\hline 1. Peace & & & & & & & & & & \\
\hline 2. Kindness & & & & & & & & & & \\
\hline 3. Warmth & & & & & & & & & & \\
\hline 4. Solidity & & & & & & & & & & \\
\hline 5. Resistance & & & & & & & & & & \\
\hline 6. Purity & & & & & & & & & & \\
\hline 7. Friendship & & & & & & & & & & \\
\hline 8. Attraction & & & & & & & & & & \\
\hline 9. Cleanness & & & & & & & & & & \\
\hline 10. Beauty & & & & & & & & & & \\
\hline 11. Hardship & & & & & & & & & & \\
\hline 12. Truth & & & & & & & & & & \\
\hline 13. Coldness & & & & & & & & & & \\
\hline 14. Depth & & & & & & & & & & \\
\hline 15. Struggle & & & & & & & & & & \\
\hline 16. Hopefulness & & & & & & & & & & \\
\hline 17. Persistence & & & & & & & & & & \\
\hline 18. Vulnerability & & & & & & & & & & \\
\hline 19. Loyalty & & & & & & & & & & \\
\hline 20. Grace & & & & & & & & & & \\
\hline 21. Love & & & & & & & & & & \\
\hline
\end{tabular}

and relate or associate those words with the column words (mostly emotional, or abstracts concepts) according to a four-level rating: 0 (no relation), 1 (low or weak relation), 2 (moderate relation), 3 (high relation). We assume these numbers as association link-the higher the number the stronger the association link.

\section{Analysis}

For the purpose of analysis, we have used descriptive statistics to provide averages. The cut-off points for consideration the items to be described and discussed as related or associated, were equal to or greater than 2 (moderate relation) and around 0.50 or lower as non-related or even negatively related, in ratings. The level of confidence has been selected as $p<0.05$ for statistical significance and $p>0.05$ for statistical non-significance. Our emphasis in this report is on the general findings regardless of the differences between groups, except in some cases such as Flower, Stone and Snow. In these cases the averages of 4 groups have been compared.

Results in the total sample

The number of cases and the means and standard deviations for age are shown in Table 2. 
Both sexes were included ( $\mathrm{N}=103 ; 58$ females and 45 males). All participants were undergraduate college students with different major areas. The averages for the scores (0 to 3$)$ in 4 languages as appear for the attributes (e.g. peace, kindness, etc.) associated with the natural phenomena (e.g. river, stone, etc.) are shown in Table 3 (because of the width of the table, SDs have not been shown).

Considering moderate to high associations (associative links equal or higher than the rough value 2) and the low associations (around 0.50 or less) the following table emerges (Table 4).

Based on the whole picture of the associations, we may come to the following Table 2. The number of cases, and means and SDs for the age of groups.

\begin{tabular}{ccc}
\hline Country & $\mathrm{N}$ & Mean(SD) \\
\hline Iran & 30 & $22.50(1.55)$ \\
Germany & 36 & $20.94(3.30)$ \\
Kuwait & 19 & $27.47(5.86)$ \\
USA & 18 & $23.12(2.60)$ \\
\hline
\end{tabular}

Table 3. The averages of associations in the total sample $(\mathrm{N}=103)$ (because of the largeness of the table, SDs have not been included).

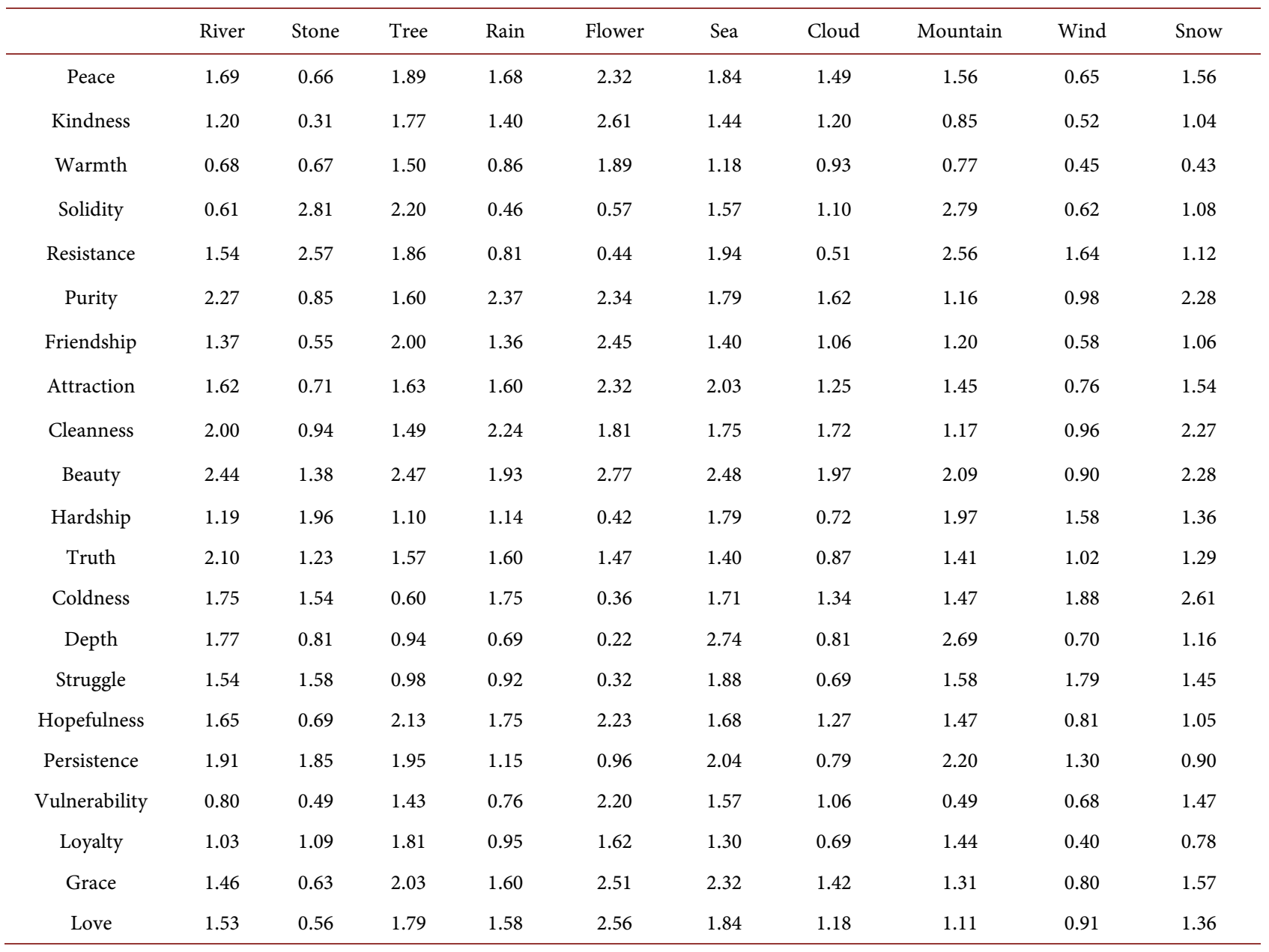


Table 4. The highest and the lowest associations.

\begin{tabular}{|c|c|c|c|c|c|c|c|c|c|c|}
\hline & River & Stone & Tree & Rain & Flower & Sea & Cloud & Mountain & Wind & Snow \\
\hline Purity & 2.27 & & & 2.37 & 2.34 & & & & & 2.28 \\
\hline Cleanness & 2.00 & & & 2.24 & & & & & & 2.27 \\
\hline Beauty & 2.44 & & 2.47 & 1.93 & 2.77 & 2.48 & 1.97 & 2.09 & & 2.28 \\
\hline Truth & 2.10 & & & & & & & & & \\
\hline solidity & & 2.81 & 2.20 & 0.46 & 0.57 & & & 2.79 & & \\
\hline Resistance & & 2.57 & & & 0.44 & & 0.51 & 2.56 & & \\
\hline Hardship & & 1.96 & & & 0.42 & & & & & \\
\hline Friendship & & & 2.00 & & 2.45 & & & & & \\
\hline Hopefulness & & & 2.13 & & 2.23 & & & & & \\
\hline Grace & & & 2.03 & & 2.51 & 2.32 & & & & \\
\hline Peace & & & & & 2.32 & & & & & \\
\hline Kindness & & 0.31 & & & 2.61 & & & & 0.52 & \\
\hline Attraction & & & & & 2.32 & 2.03 & & & & \\
\hline Vulnerability & & 0.49 & & & 2.20 & & & & & \\
\hline Love & & 0.56 & & & 2.56 & & & 2.69 & & \\
\hline Depth & & & & & 0.22 & 2.74 & & & & \\
\hline Persistence & & & 1.95 & & & 2.04 & & 2.20 & & \\
\hline Coldness & & & & & 0.36 & & & & 1.88 & 2.61 \\
\hline Warmth & & 0.67 & & & & & & & 0.45 & 0.43 \\
\hline Struggle & & & & & 0.32 & & & & & \\
\hline Loyalty & & & & & & & & & 0.40 & \\
\hline
\end{tabular}

clusters (the underlined items represent the highest rate):

River [purity, cleanness, beauty, truth]

Stone [solidity, resistance, hardship (marginal)]

Tree [beauty, solidity, friendship, hopefulness, grace, persistence (marginal)]

Rain [purity, cleanness, beauty (marginal)]

Flower [purity, beauty, friendship, hopefulness, grace, peace, kindness, attraction, vulnerability, love]

Sea [beauty, grace, attraction, depth, persistence]

Cloud [beauty (marginal) $]$

Mountain [beauty, solidity, resistance, depth, persistence]

Wind [coldness (marginal)]

Snow [purity, cleanness, beauty, coldness]

If we prefer to mention just one attribute for natural phenomena, the following associations would be the most salient attributes:

River beauty

Stone solidity 


$\begin{array}{ll}\text { Tree } & \text { beauty } \\ \text { Rain } & \text { purity } \\ \text { Flower } & \text { beauty } \\ \text { Sea } & \text { depth } \\ \text { Cloud } & \text { beauty? } \\ \text { Mountain } & \text { solidity } \\ \text { Wind } & \text { coldness? } \\ \text { Snow } & \text { coldness }\end{array}$

\section{General Discussion: Some Findings in the Total Sample}

The attributes such as solidity, purity, depth and coldness are expected to be related to Stone, Rain, Sea and Snow, but beauty is something which tends to be represented by different natural phenomena: River (highest association), Tree (highest association), Flower (highest association), Sea (high association), Cloud (high association), Mountain (high association), Rain (high association), and Snow (high association). It seems whenever we are dealing with some "abstract" concepts which it is difficult to put them in a well-defined category, the sense of beauty may show itself in different objects or relations. What is important is not necessarily the object itself but the combination of some salient features on the one hand and the mental set that is activated in the individual, on the other. However, some objects may represent beauty better than others. For example, in this study Flower is the best representative of beauty, but not the only one (Figure 1).

We may look from the other side to find the best representatives (Table 5). In this case we may check the highest rates of associative links between the attributes and the nouns. It is interesting that Flower is the most capable object to represent different attributes: Peace, Kindness, Friendship, Attraction, Beauty, Hopefulness, Vulnerability, but its highest rate of association belongs to Beauty.

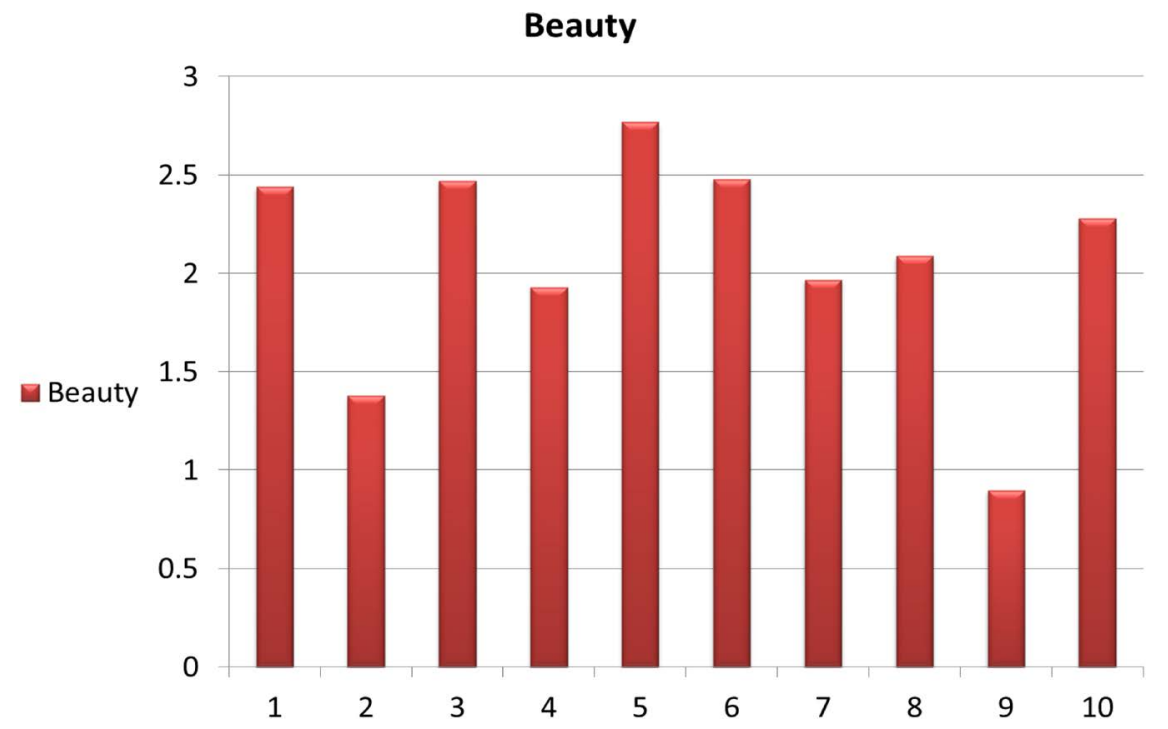

Figure 1. Beauty as represented in Flower and other natural phenomena. 
Table 5. The highest associations as reflected in the attributes.

\begin{tabular}{|c|c|c|c|c|c|c|c|c|c|c|}
\hline & River & Stone & Tree & Rain & Flower & Sea & Cloud & Mountain & Wind & Snow \\
\hline Peace & & & & & $\underline{2.32}$ & & & & & \\
\hline Kindness & & & & & $\underline{2.61}$ & & & & & \\
\hline \multicolumn{11}{|l|}{ Warmth } \\
\hline Solidity & & $\underline{2.81}$ & & & & & & 2.79 & & \\
\hline Resistance & & $\underline{2.57}$ & & & & & & 2.56 & & \\
\hline Purity & 2.27 & & & $\underline{2.37}$ & 2.34 & & & & & 2.28 \\
\hline Friendship & & & & & $\underline{2.45}$ & & & & & \\
\hline Attraction & & & & & $\underline{2.32}$ & & & & & \\
\hline Cleanness & & & & 2.24 & & & & & & $\underline{2.27}$ \\
\hline Beauty & 2.44 & $\underline{1.96}$ & 2.47 & & $\underline{2.77}$ & & & & & \\
\hline \multicolumn{11}{|l|}{ Hardship } \\
\hline Truth & $\underline{2.10}$ & & & & & & & & & \\
\hline Coldness & & & & & & & & & & $\underline{2.61}$ \\
\hline Depth & & & & & & $\underline{2.74}$ & & 2.64 & & \\
\hline \multicolumn{11}{|l|}{ Struggle } \\
\hline Hopefulness & & & & & $\underline{2.23}$ & & & & & \\
\hline Persistence & & & & & & 2.04 & & $\underline{2.20}$ & & \\
\hline Vulnerability & & & & & $\underline{2.20}$ & & & & & \\
\hline \multicolumn{11}{|l|}{ Loyalty } \\
\hline Grace & & & & & $\underline{2.51}$ & 2.32 & & & & \\
\hline Love & & & & & $\underline{2.56}$ & & & & & \\
\hline
\end{tabular}

This may be one the reasons that Flower is used in many different and sometimes opposite occasions. Because of the importance of Flower in daily life and its high potential to play the role of source domain for a wide range of meanings (target domains), we discuss the matter with some details.

Flower as the representative of Beauty, Kindness and Love

Let's consider the concept of beauty, kindness and love. According to our findings the most representative natural phenomenon for beauty in our samples based on the average scores is Flower, which was expected. The average scores were $2.77,3.00,2.56$, and 2.74 for Iran, USA, Germany and Kuwait, respectively. The mean for these averages was 2.77. There are other associations but not as high as in the case of flower: such as River, Tree, Rain, Sea, Cloud, Mountain, and Snow. Kindness was also highly related to Flower. The average scores in this regard were 2.50, 2.22, 2.95, and 2.78 for Iran, Germany, Kuwait, and USA, respectively. The mean for these averages was 2.61. Love finds its most representative expression in Flower as well. The average scores for this expression in 4 groups are: 2.67 (Iran), 2.72 (USA), 2.11 (Germany) and 2.74 (Kuwait). The mean for the averages is 2.56 . 
In a way, we may say that Flower plays a role of source domain for the concept of beauty, kindness and love. Consistent with our findings, there are many indications of love, kindness and beauty in the literature.

Now we can illustrate the other way to examine the links between Flower and different attributes (Figure 2).

Again, we can see a kind of consistency between groups. But beauty is not the only peculiarity of Flower-although it is the most accessible to the mind of people. The other concepts, such as Kindness, Hopefulness, Vulnerability, Grace, Love, and Friendship may also find their most salient expressions in Flower.

\section{Flower and Vulnerability}

Vulnerability has been found to be one of the attributes of Flowers in this study. A Flower is beautiful but at the same time it is perishable. Sa'di of Shiraz (1210-1291) tells us an interesting story in the introduction of his famous book Gulistan (Rose Garden). When he returns from his long trip, he decides to spend the rest of his life in continual devotion and silence in spite of his friends' request to write down his biography and the whole experience that he had accumulated during his more than 30-year tourism. But one day morning when he sees his friend has in his skirt collected colorful flowers, he changes his mind and tells the friend that the roses of the garden are perishable and continues "whatever is not of long duration is not to be cherished". Then he decides to compose a book as a rose garden "whose leaves cannot be touched by tyranny of autumn blasts and the delight of whose spring the vicissitudes of time will be unable to change into the inconsistency of autumn".

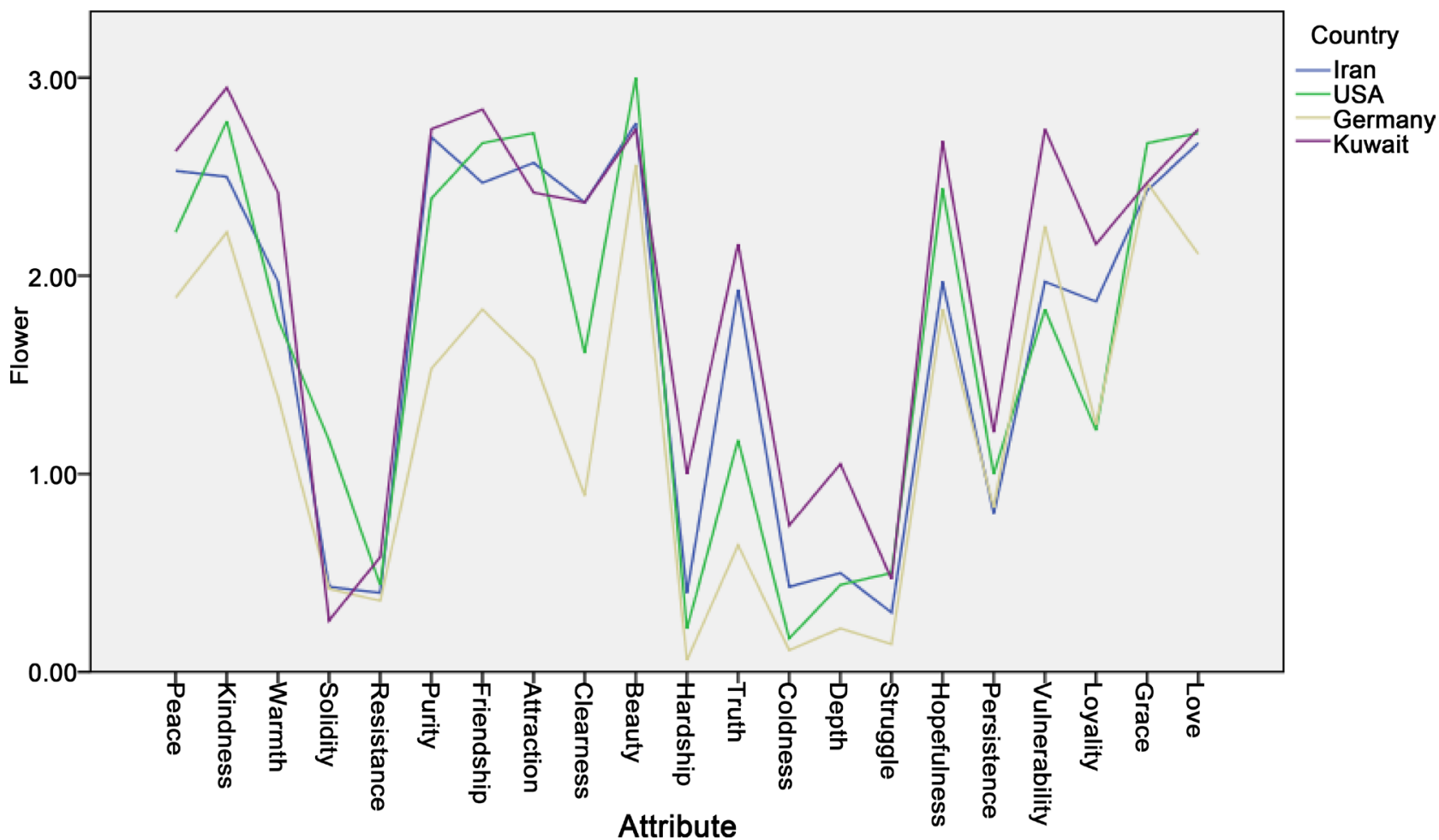

Figure 2. The links between Flower and different attributes. 
Of what use will be a dish of roses to thee?

Take a leaf from my rose garden.

A flower endures but five or six days,

But this Rose Garden is always delightful (Sa'di, 1987/1366).

Stone and Snow

A basically different scenario from Flower belongs to Stone and Snow. In our study Warmth did not have any representatives but its low associative link with items such as Snow, Wind and Stone is consistent with the common sense. When we say "Snow is cold" or sometimes "Wind is cold" no one would argue with us but when we say that

"Stone is cold" we may encounter with non-expected judgment from the audience. This is because Coldness which has been accepted as a natural attribution of Snow has not been necessarily referred as a natural feature of Stone.

Every word is able to activate a semantic network of associations. Some associations may be stronger-more readily accessible in the working memorythan others in terms of the activation. One possible mechanism for activation of a source domain to play a mapping role in metaphor processing is providing an associative link with the target domain. This associative link can be interpreted as a link which is most available in the memory and can be activated very easily through a cue-most often a word.

The image or idea that comes to mind seems to be a function of two processes: 1) an excitatory effect, which activates a semantic field in general; and 2) an inhibitory effect which helps the working memory to select the most relevant or related idea or image from the assembly or collection of many options. This is usually done through an inhibition which blocks the way of many incoming options.

Stone has been related to Solidity, Resistance, Hardship and Persistence in this study. The lowest rating goes with Kindness. In other words, when we are talking about Kindness, one of the links that might be inhibited in the brain is the association between Stone and Kindness. This inhibition, in turn activates the alternative link which belongs to Stone and Coldness (as an opposite to Kindness). Thus, one of the metaphorical meanings of Stone in everyday language is a lack of feeling or expression or movement: "he must have a heart of stone" or "her face was hard as stone." In this sense, Stone cannot be kind, which reflects itself in a low near to zero association to kindness in our study.

In Snow assessment, the highest rating belongs to Coldness-which was expected. The other ratings are: Beauty, Cleanness, and Purity. Vulnerability was also rated as high. The lowest rating is related to Warmth which is not unusual.

Snow is mostly representative of being white, pure white. The connection between whiteness and snow is a modality based connection as far as the "literal" meaning is concerned. But when we speak metaphorically-in Persian language-we use the expression of "Snow of oldness on the head", the white color is reflected in the word Snow. The other implications of Snow are coldness, purity, 


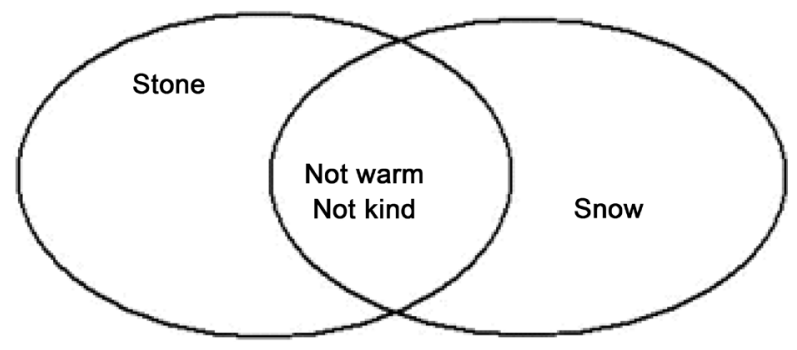

Figure 3. High and low associations for Stone and Snow.

beauty and cleanness and vulnerability. High and low associations of Stone and Snow are shown in Figure 3.

$\begin{array}{lll} & \begin{array}{l}\text { High Association } \\ \text { Purity }\end{array} & \text { Low or no Association } \\ \text { Snow } & \begin{array}{l}\text { Cleanness } \\ \text { Beauty }\end{array} & \text { Warmth } \\ \text { Coldness } & \\ \text { Stone } & \begin{array}{l}\text { Solidity } \\ \text { Resistance } \\ \text { Hardship }\end{array} & \\ & \text { Kindness }\end{array}$

It is interesting to note that stone and snow, two apparently different phenomena share on one peculiarity, namely "coldness". In other words, as Glucksberg $(2003 ; 2008)$ suggests they belong to the same category regarding the concept of coldness. Coldness for Snow is a naturalistic peculiarity, but for Stone is reflecting something such as "not moving", "not being impressed by" or "not being responsive". There is a low or a negative relation or association between warmth and snow, and between kindness and stone. Kindness and warmth, on the other hand, are correlated.

\section{Some Reflections on the General Findings}

How Flower gets Warm and Kind, and Stone and Snow come together. The case of embodied cognition

In our study Mountain has been related to the concepts such as Solidity, Resistance, Hardship, Persistence, Beauty and Struggle. The lowest ratings are related to Vulnerability and Warmth. There is no doubt that mountain itself is just a natural phenomenon. The attributes such as Solidity and Hardship are human-related meanings that have been generated in the process of interaction with Mountain. They are experiential phenomena with an association basis. Therefore, we use statements like "he has a mountain to climb" (it will be difficult for him/her to achieve what he/she wants to achieve) or "to move mountains" means to achieve spectacular results. The same explanation is true about Cloud, Rain, Stone, etc. Stone is a solid thing for human being but not for machines. Therefore, many characteristics of environment are in a way human-related experience and as such represent many aspects of human body and perception as have been formulated in embodiment theory. 
The relevance of our findings to embodiment theory is impressing. Embodiment is defined as a complex process that involves representations of the self and the body, multi-sensory integration and motor intention and function (Giummarra et al., 2008: 151). Landau, Meier and Keefer (2010) have made a distinction between conceptual metaphor and embodied cognition. They have considered conceptual metaphor as an inter-conceptual and embodied simulation as an intra-conceptual mechanism. In the first one some notions are systematically structured in terms of different concepts (e.g. between physical warmth and friendship). But in the second one modality-specific representation about a given concept from prior experiences substitute a new experience belonged to that concept. In this case concepts contain representations of bodily states that occur in the process of interactions with concept-relevant stimuli (e.g. bodily states including temperature-related sensations occur during friendly interpersonal encounters) (p. 1054). Best representative (associated to the highest rating) of Warmth has been indicated as Flower in our study. In addition, all of the groups were consistent on the lowest association between Warmth and Stone and Warmth and Snow. It is interesting that Kindness, Friendship, Attraction, Beauty, Hopefulness, Vulnerability, Loyalty, Grace, and Love have also found their highest ratings in Flower. Then, Flower has an association with Warmth on one hand and the emotional concepts such as Kindness, Friendship, Attraction, Beauty and Hopefulness, on the other. It seems when we are dealing with high-level or combined concepts the mediation of these processes would in part depend on the associations or semantic field. In the processing of an abstract concept two mechanisms may be involved: 1) simulation of bodily states related to that concept; and 2) metaphoric mappings between that concept and the concept derived from embodied experience. Flower is not warm, but it is a cue for a warm relationship. Therefore, a mediating process is going on here which is mostly related to memory structure and organization as well as cultural factors.

Let's examine the relevance of Snow and Stone to some metaphors as an important expression of associative meaning. Grady (2005) believes that the primary metaphors (metaphors such as affection is warmth) are the basis for so many figurative conceptualizations. In his view coldness and lack of emotion are fundamentally different and incommensurable, just as height and quantity are. The association in our experience is so strong that the aloofness of a group of people is felt to be similar to the coldness of a glacier unless we focus consciously on the relationship between them. People "just do" think in terms of such metaphoric patterns and the blends which build upon them (Grady, 2005: 1612-1613).

It is interesting that Snow by itself does not reflect coldness when we refer to a person. Although snow, in this study has had the highest associative link with coldness (physical), in everyday communication, snow is not usually used as a representative of coldness metaphorically. People use the word "ice" instead. We read in the newspapers that “Michael Brown's family Attorney Benjamin Crump 
said Ferguson Police Officer Wilson was as 'cold as ice'." The attorney did not use the word "snow" as a representative of "coldness" to convey lack of feeling, affection and being indifferent to what happens to other people. For some reason Snow has not been used as a prototype of coldness in everyday language, the word "ice" has taken this position. It seems feeling cold requires something more than snow, something like solidity and endurance.

There are many indications of temperature as an index of social proximity in the literature (for example, "accept my warm wishes"). Lakoff and Johnson (1999) believe that in this case an abstract concept such as affection is explained and experienced through a concrete notion of temperature which can be graded and measured. This kind of association has been called embodied realism in cognitive science.

Warmth is one the most important concepts which is used in the process of judging other people's behavior, temperament and personality (Asch, 1946; Fiske, Cuddy, \& Glicke, 2007). There have been some explanations about this relation or association. (Barsalou's 1999; 2008; 2010; Barsalou et al., 2003) ideas about grounded cognition provides a basis for such a relation. According to him the "modal simulations, bodily states, and situated action underlie cognition" (Barsalou, 2008: 617). This idea is consistent with the experiential correlation hypothesis of Lakoff and Johnson (1999) about metaphor. They believe that "affection is warmth" as a metaphor can be understood in the process of "co-experiencing", which goes back to the relation of babies with their mothers. Later, this relation becomes consolidated by experiential correlation. Studies have shown that in our everyday life affection is induced by warmth and the insular cortex is involved in processing both psychological and physical warmth (Williams \& Bargh, 2008).

Metaphors such as "the cold shoulder" or "a cold fish", on the one hand and "warm embrace" or "giving a warm welcome" on the other, all represent linking warmth to social proximity. In other words, an abstract concept of affection which is not very easy to define or to grasp its exact meaning is understood by another concrete notion as warmth or coldness.

Damasio's (2003) explanation about the relation between affectivity and temperature may also be relevant to our discussion about experiential basis of metaphorical meaning. According to Damasio (2003) the feeling of an emotion is associated with skin temperature. We evaluate a relationship "cold" because of the coldness that we feel in that relationship and vice versa.

In this context the relation can be analyzed in two ways: 1 ) interacting with a cold object and interacting with an unfeeling person are perceived as similar experiences; and 2) through recurring experience we associate the conceptual domain of temperature with that of the unfeeling person. In other words, there is a conceptual association between coldness and lack of feeling (Grady, 2005: 1600). It is through this mechanism that Stone gets close to Ice as mentioned before.

The relation between changes in skin temperature and the degree of arousal 
during interpersonal interactions has been shown in a study by Hahn et al. (2012). In another study, Zhong and Leonardelli (2008) found that individuals who are left alone in a room feel the temperature cooler and like to have warmer drinks. Even another person's gaze has been shown to be effective in psycho-physiological responses (Loannou et al., 2014).

Therefore, there is a parallel experience between temperature and feeing in the course of life starting from childhood through adulthood. As a matter of fact we learn such a relation and it plays a role in our evaluations as well as judgments. Even the temperature may influence our perception of another person as more sociable or unsociable (Williams \& Bargh, 2008).

It is interesting to note that in metaphors such as "she is a warm person" the direction of understanding and experiencing most often is from affection toward physical warmth (but not vice versa). This is called "unidirectionality" hypothesis by Lakoff and Johnson (1999). It seems it is the physical warmth that becomes an integral part of the affection not vice versa. This is what has been suggested in the mental representation literature (cf. Landau et al., 2011).

We as a child start our experience mostly as sense-dominated and cross-wiring. Ramachandran (2004) has shown that we are all born with excess or redundant connections in the brain which get pruned away in the course of development. But in some cases-one in 200-this pruning gene is defective and therefore, synesthesia or cross-wiring or cross-activation may occur. The individual with synesthesia may see colors in numbers, days, and months. This experience is the result of cross-activation between adjacent parts of the brain that are normally only loosely connected.

Luria's case Solomon V. Shereshevsky or "S" experienced synesthetic reactions when he listened to someone's voice. He once told Vygotsky, "What a crumbly yellow voice you have" (Luria, 2002: 24). This statement looks very similar to some poetic expressions. Are poets synesthete? Ramachandran believes that artists, poets and novelists all have in common the skill at linking seemingly unrelated concepts in their brain and producing metaphors. But there is a difference between synesthesia and metaphor. He talks about a gene responsible for such a cross-activation. If the gene is expressed in the fusiform (part of Brodmann area 37), we have a lower synesthesia, if the gene is expressed in the angular/temporal, parietal, occipital junction we have a higher synesthesia. But if is expressed everywhere-cross-modally-there is a greater hyper-connectivity throughout the brain, making that statement most similar to metaphor-the ability to link seemingly unrelated things (Ramachandran, 2004: 71).

In general we can summarize our theoretical analysis and the result of our pilot study as follows:

1) The concept of meaning has changed in the history of psychological and cognitive sciences.

2) At first, meaning was supposed to be a totally abstract and stable representation in mind. But later it changed to be a direct and mostly unconscious prod- 
uct of experience, and therefore, the meaning became something which can be sensed, touched and perceived.

3) Consistent with the changes that happened in the conceptualization of meaning, the approach to the measurement of meaning changed from the association of ideas-as abstract entities-to the association of different sensorimotor experiences as happen in the relation between the individual and the environment.

4) Moving in this direction, it became evident that human thought processes, including the meanings are largely embodied and metaphorical. Our experience of physical objects-e.g. natural phenomena-provides a basis for understanding the things or events which are categorized as "non-physical". Therefore, "affection" signifies "warm" and "isolation" is experienced as "cold".

5) The study that we reported here part of its findings may be regarded as a pilot study to explore more about the cross-cultural and cross-linguistic nature of meaning as expresses itself in the primary metaphors formulations. Is "Flower" evaluated "beautiful" in all cultures and languages? "Rain" and "Raining" may be related to the ideas of good agricultural products in most dry countries leading to some positive emotional concepts such as Cleanness, Purity, Joyfulness and Hopefulness. But the people who live in Far East or in some western countries may not have such a positive attitude toward "Rain" and "Raining".

6) Our main focus in this study and discussion was to provide a basis for an integrated perspective in which the old ideas of associative link and the concept of semantic field on the one hand and embodiment theory and findings on the other, are interwoven through an experiential mechanism. Metaphors are the products of such a mechanism.

\section{Limitations}

We are aware of the limitations of this project and discussion. First of all, the number of subjects was very small and they had not been selected randomly from different populations. We were also not able to take more languages into consideration. Culture and language are interwoven and the semantic fields of the people are influenced strongly by these factors. For example, the concept of "house" and its various parts or sections and associations may be different from the people living in different conditions with different incomes. A dining room or a room for guests is a part of home for most people of rich countries. But there is no such space in the houses of most poor societies. Therefore, guest room may not be a part of the concept of house in the mind of these people. On the other hand, in studies related to associations, reaction time is very important, which has not been considered in this work. Obviously, for the purpose of relating all of these associations to different areas or circuits of the brain, appropriate design is required using fMRI or other relevant neurological techniques.

Besides the mentioned limitations, there are still some debates about the role 
of right or left hemisphere (RH, LH) in the processing of different types of figurative language (Faust \& Lavidor, 2003; Faust \& Mashal, 2007; Gazzaniga, 2000). The distinction between conventional and novel metaphoric expressions with regard to the differential processing by the $\mathrm{LH}$ and $\mathrm{RH}$, respectively, has been realized consistent with the graded salience hypothesis. In this hypothesis, developed by Giora (1997; 2002), it is the degree of semantic salience (i.e., familiarity, frequency, prominence, conventionality, proto-typicality, contextual independence) rather than the literal/metaphorical meaning of a linguistic expression that is important. According to this model, the LH/literal meaning versus $\mathrm{RH} /$ metaphoric meaning dichotomy may be replaced by $\mathrm{LH} /$ salient meanings versus RH/non-salient meanings dichotomy (Pobric et al., 2008: 171). This is an important claim which may change the whole direction of research in the near future.

\section{Acknowledgements}

The main part of this article was written during two summers (2012 and 2014) that I spent in Eugene, Oregon, while on my leave from Tehran University of Medical Sciences. I would like to thank Professors Michael Posner and Holly Arrow for their invitation and providing me with an office space in the Institute of Cognitive and Decision Sciences (ICDS), University of Oregon. I also would like to express my gratitude to Professor Mark Johnson, Department of Philosophy, University of Oregon, for his invaluable comments on the content of the manuscript and the organization of the paper. We have had many lively discussion sessions in his office. Although he was not in agreement with me on some theoretical formulations and interpretations of the work, his encouragement and tolerance were admirable.

\section{Conflict of Interest Statement}

The authors declare that the research was conducted in the absence of any commercial or financial relationships that could be construed as a potential conflict of interest.

\section{References}

Asch, S. (1946). Forming Impressions of Personality. Journal of Abnormal and Social Psychology, 41, 258-290. https://doi.org/10.1037/h0055756

Barsalou, L. W. (1999). Perceptual Symbol System. Behavioral and Brain Sciences, 22, 577-660. https://doi.org/10.1017/S0140525X99002149

Barsalou, L. W. (2008). Grounded Cognition. Annual Review of Psychology, 59, 617-645. https://doi.org/10.1146/annurev.psych.59.103006.093639

Barsalou, L. W. (2010). Grounded Cognition: Past, Present, and Future. Topics in Cognitive Science, 3, 345-351. https://doi.org/10.1111/j.1756-8765.2010.01115.x

Barsalou, L. W., Simmons, W. K., Barbey, A. K., \& Wison, C. D. (2003). Grounding Conceptual Knowledge in Modality-Specific Systems. Trends in Cognitive Science, 7, 84-91. 
Billow, R. M. (1977). Metaphor: A Review of the Psychological Literature. Psychological Bulletin, 84, 81-92. https://doi.org/10.1037/0033-2909.84.1.81

Carrol, D. W. (1999). Psychology of Language (3rd ed.). Pacific Grove, CA: Brooks/Cole.

Chandler, D. (2002). Semiotics: The Basics. New York, NY: Routledge. https://doi.org/10.4324/9780203166277

Damasio, A. (2003). Looking for Spinoza: Joy, Sorrow, and the Feeling Brain. Orlando, FL: Harcourt.

Deignan, A. (2003). Metaphorical Expressions and Culture: An Indirect Link. Metaphor and Symbol, 18, 255-271. https://doi.org/10.1207/S15327868MS1804_3

Faust, M., \& Lavidor, M. (2003). Convergent and Divergent Priming in the Two Cerebral Hemispheres: Lexical Decision and Semantic Judgment. Cognitive Brain Research, 17, 585-597.

Faust, M., \& Mashal, N. (2007). The Role of Right Cerebral Hemisphere in Processing Novel Metaphoric Expressions Taken from Poetry: A Divided Visual Field Study. Neuropsychologia, 45, 860-870.

Feldman, J. A. (2008). From Molecule to Metaphor-A Neural Theory of Language. Cambridge: MIT Press.

Fiske, S. T., Cuddy, A. J. C., \& Glicke, P. (2007). Universal Dimensions of Social Cognition: Warmth and Competence. Trends in Cognitive Sciences, 11, 77-83.

Frege, G. (1892/1970). On Sense and Reference. In Translations from the Philosophical Writings of GottlobFrege (pp. 56-78). Oxford : Basil Blackwell.

Gallese, V., \& Lakoff, G. (2005). The Brain's Concepts. Cognitive Neuropsychology, 22, 455-479. https://doi.org/10.1080/02643290442000310

Gazzaniga, M. S. (2000). Cerebral Specialization and Interhemispheric Communication: Does the Corpus Callosum Enable the Human Condition? Brain, 123, 1293-1326. https://doi.org/10.1093/brain/123.7.1293

Ghassemzadeh, H. (1999). Some Reflections on Metaphoric Processing: A Move toward a Meta-Sign Formulation. New Ideas in Psychology, 17, 41-54.

Ghassemzadeh, H. (2005). Vygotsky's Mediational Psychology: A New Conceptualization of Culture, Signification and Metaphor. Language Sciences, 27, 281-300.

Gibbs, R. W. (1994). The Poetics of Mind-Figurative Thought, Language, and Understanding. Cambridge: Cambridge University Press.

Gibbs, R. W. (1996). Why Many Concepts are Metaphorical. Cognition, 61, 309-319.

Gibbs, R. W. (1998). The Fight over Metaphor in Thought and Language. In A. N. Katz et al. (Eds.), Figurative Language and Thought (pp. 88-118). New York, NY: Oxford University Press.

Gibbs, R. W. (1999). Taking Metaphor Out of Head and Putting It and Putting It in the Cultural World. In R. W. Gibbs, \& G. J. Steen (Eds.), Metaphor in Cognitive Linguistics (pp. 146-166). Amsterdam: John Benjamins. https://doi.org/10.1075/cilt.175.09gib

Gibbs, R. W. (2005). Embodiment and Cognitive Science. New York, NY: Cambridge University Press. https://doi.org/10.1017/CBO9780511805844

Giora, R. (1997). Understanding Figurative and Literal Language: The Graded Salience Hypothesis. Cognitive Linguistics, 7, 183-206. https://doi.org/10.1515/cogl.1997.8.3.183

Giora, R. (2002). Literal vs. Figurative Language: Different or Equal? Journal of Pragmatics, 34, 487-506.

Giummarra, M. J., Gibson, S. J., Georgiou-Karistianis, N., \& Bradshaw, J. L. (2008). Me- 
chanisms Underlying Embodiment, Disembodiment and Loss of Embodiment. Neuroscience and Biobehavioral Reviews, 32, 143-160.

Glucksberg, S. (2003). The Psycholinguistics of Metaphor. Trends in Cognitive Sciences, 7, 92-96.

Glucksberg, S. (2008). How Metaphors Create Categories Quickly. In R. W. Gibbs, (Ed.), The Cambridge Handbook of Metaphor and Thought (pp. 67-73). Cambridge: Cambridge University Press. https://doi.org/10.1017/CBO9780511816802.006

Grady, J. (2005). Primary Metaphors as Inputs to Conceptual Integration. Journal of Pragmatics, 37, 1595-1614.

Graham, A. (1985). Psycholinguistics-Central Topics. London: Routledge.

Hahn, A. C., Whitehead, R. D., Albrecht, M., Lefevre, C. E., \& Perrett, D. I. (2012). Hot or Not? Thermal Reactions to Social Contact. Biology Letters, 8, 864-867.

https://doi.org/10.1098/rsbl.2012.0338

Hebb, D. O. (1949). Organization of Behavior. New York, NY: John Wiley.

Johnson, M. (2007). The Meaning of the Body. Aesthetics of Human Understanding. Chicago: University of Chicago Press. https://doi.org/10.7208/chicago/9780226026992.001.0001

Jung, C. G. (1918). Studies in Word-Association. London: William Heinemann Ltd.

Kent, G. H., \& Rosanoff, A. J. (1910). A Study of Association in Insanity. American Journal of Insanity, 67, 37-96.

Keshavarz, F., \& Ghassemzadeh, H. (2008). Life as a Stream and the Psychology of "Moment" in Hafiz'verse: Application of the Blending Theory. Journal of Pragmatics, 40, 1781-1798.

Kovecses, Z. (2005). Metaphor in Culture: Universality and Variation. Oxford: Oxford University Press. https://doi.org/10.1017/CBO9780511614408

Lakoff, G. (1993). The Contemporary Theory of Metaphor. In A. Ortony (Ed.), Metaphor and Thought (pp. 202-251). New York, NY: Cambridge University Press. https://doi.org/10.1017/CBO9781139173865.013

Lakoff, G. (2008). The Neural Theory of Metaphor. In R. W. Gibbs (Ed.), The Cambridge Handbook of Metaphor and Thought (pp. 17-38). Cambridge: Cambridge University Press. https://doi.org/10.1017/CBO9780511816802.003

Lakoff, G., \& Johnson, M. (1980/2003). Metaphors We Live By. Chicago: The University of Chicago Press.

Lakoff, G., \& Johnson, M. (1999). Philosophy in the Flesh. New York, NY: Basic Books.

Lakoff, G., \& Turner, M. (1989). More than Cool Reason-A Field Guide to Poetic Metaphor. Chicago: The University of Chicago Press. https://doi.org/10.7208/chicago/9780226470986.001.0001

Landau, M. J., Meier, B. P., \& Keefer, L. A. (2010). A Metaphor-Enriched Social Cognition. Psychological Bulletin, 136, 1045-1067. https://doi.org/10.1037/a0020970

Landau, M. J., Vess, M., Arndt, J., Rothschild, Z. K., Sullivan, D., \& Atchley, R. A. (2011). Embodied Metaphor and the "True" Self: Priming Entity Expansion and Protection Influences Intrinsic Self-Expressions in Self-Perceptions and Interpersonal Behavior. Journal of Experimental Social Psychology, 47, 79-87.

Loannou, S., Morris, P., Mercer, H., Baker, M., Gallese, V., \& Reddy, V. (2014). Proximity and Gaze Influences Facial Temperature: A Ther Malinfrared Imaging Study. Frontiers in Psychology, 5, 1-12.

Luria, A. R. (1982). Language and Cognition. New York, NY: Wiley-Interscience. 
Luria, A. R. (2002). The Mind of a Mnemonist-A Little Book about a Vast Memory. Cambridge: Harvard University Press.

Lyons, J. (1968). Introduction to Theoretical Linguistics. London: Cambridge University Press.

Martindale, C. (1990). Cognitive Psychology-A Neural-Network Approach. Pacipc Grove, CA: Brooks/Cole Publishing Company.

Ogden, C. K., \& Richards, I. A. (1923). The Meaning of Meaning. London: Routledge \& Kegan Paul.

Ortony, A. (1975). Why Metaphors Are Necessary and Not Just Nice. Educational Theory, 25, 45-53. https://doi.org/10.1111/j.1741-5446.1975.tb00666.x

Ortony, A. (1979a). Beyond Literal Similarity. Psychological Review, 86, 161-180. https://doi.org/10.1037/0033-295X.86.3.161

Ortony, A. (1979b). Metaphor: A Multidimensinal Problem. In A. Ortony (Ed.), Metaphor and Thought (pp. 1-16). Cambridge: Cambridge Press.

Ortony, A., Reynolds, R. E., \& Arter, J. A. (1978). Metaphor: Theoretical and Empirical Research. Psychological Bulletin, 85, 919-943. https://doi.org/10.1037/0033-2909.85.5.919

Osgood, C. E. (1953). Method and Theory in Experimental Psychology. New York, NY: Oxford.

Osgood, C. E. (1964). Semantic Differential Technique in the Comparative Study of Cultures. American Anthropologist, 66, 171-200.

Osgood, C. E., May, W. H., \& Miron, M. S. (1975). Cross-Cultural Universals of Affective Meaning. Chicago: University of Illinois Press.

Osgood, C. E., Susi, G. J., \& Tannebaum, P. H. (1957). The Measurement of Meaning. Urbana: University of Illinois Press.

Pobric, G., Mashal, N., Faust, M., \& Lavidor, M. (2008). The Role of the Right Cerebral Hemisphere in Processing Novel Metaphoric Expressions: A Transcranial Magnetic Stimulation Study. Journal of Cognitive Neuroscience, 20, 170-181. https://doi.org/10.1162/jocn.2008.20005

Ramachandran, V. S. (2004). A Brief Tour of Human Concsciousness. New York, NY: PI Press.

Sa'di, M. (1987). Kulliyate Sa'di (Collected Works of Sa'di). Tehran: Amir Kabir.

Slobin, D. I. (1974). Psycholinguistics. Glenview, IL: Scott, Foresman and Company.

Vygotsky, L. S. (1962). Thought and Language. Cambridge: The MIT Press. https://doi.org/10.1037/11193-000

Williams, L. E., \& Bargh, J. A. (2008). Experimental Physical Warmth Promots Interpersonal Warmth. Science, 323, 606-607. https://doi.org/10.1126/science.1162548

$\mathrm{Yu}, \mathrm{N}$. (2008). Metaphor from Body and Culture. In R. W. Gibbs (Ed.), The Cambridge Handbook of Metaphor and Thought (pp. 247-261). Cambridge: Cambridge University Press. https://doi.org/10.1017/CBO9780511816802.016

Zhong, C.-B., \& Leonardelli, G. J. (2008). Cold and Lonely. Pschological Science, 19, 839-842. https://doi.org/10.1111/j.1467-9280.2008.02165.x 